\title{
INTRODUKSI PRODUK BANANA CHIP AREN SUGAR DAN BANANA PUDING PADA IBU-IBU DAN REMAJA NYAPAH WALANTAKA, SERANG
}

\author{
${ }^{1)}$ Dini Martinda Lestari, ${ }^{2}$ Surti Zahra \\ Fakultas Ekonomi dan Bisnis, Universitas Bina Bangsa \\ ${ }^{1)}$ Email : dmartinda77@gmail.com \\ ${ }^{2)}$ Email : zahra3803@gmail.com
}

\begin{abstract}
Abstrak
Pisang memiliki sekitar 136 kalori untuk setiap 100 gram yang secara keseluruhan berasal dari karbohidrat yang mempunyai manfaat kesehatan dan gizi, sehingga perlu disebarluaskan di masyarakat. Program pengabdian kepada masyarakat ini bertujuan untuk memberikan solusi untuk permasalahan yang ada di kelurahan Nyapah khusus nya bagi penghasil keripik pisang yaitu kurang nya kualitas barang yang di jual dan di produksi di daerah tersebut. Untuk itulah di lakukan kegiatan program pembinaan mulai dari meningkatkan pemahaman masyarakat sasaran terkait pengolahan pisang menjadi berbagai produk inovasi, serta memberikan pengetahuan manfaat pisang dari aspek gizi, dan kesehatan. Khalayak sasaran dalam kegiatan ini adalah ibu-ibu dan remaja kelurahan Nyapah, kecamatan Walantaka, Serang Banten. Metode kegiatan terdiri dari sosialisasi, seminar UMKM dan Baksos Kesehatan serta pada saat Loka Karya Kelurahan. Luaran yang telah di capai dari pelaksanaan program pengabdian yaitu sebagai berikut : 1 . Pemahaman tentang kesehatan dan manfaat produk pisang yang di produksi 2.Peningkatan kualitas produk pisang dan kualitas kemasan proses packaging 3. Peningkatan Penghasilan sebesar 50\%. 4. Artikel Ilmiah.
\end{abstract}

Kata Kunci : Pisang, Banana Chip, Banana Puding, Introduksi 


\section{PENDAHULUAN}

Kelurahan Nyapah merupakan kelurahan yang berada di kota Serang tepatnya di Kecamatan walantaka dimana dalam bidang ekonominya masyarakat Nyapah Bertani, berkebun dan berdagang. Salah satu item yang di butuhkan untuk mengembangkan usaha dan produksi nya adalah sumber daya atau bahan baku. masyarakat kelurahan Nyapah memiliki potensi dalam bidang pertanian dan perkebunan yang lebih tinggi potensinya dalam bidang perkebunan pisang diantaranya: mengembangkan pengolahan terhadap sumber daya pertaniannya seperti pisang dan pengembangan terhadap penjualan produk yang sudah ada didaerah Nyapah. Penanaman pohon pisang ini sendiri cukup banyak di kelurahan nyapah. Sehingga dapat dikembangkan demi mengembangkan perekonomian masyarakat. Pisang ini juga bisa digunakan sebagai pengganti makanan, cemilan santai dan lain-lain.

Kekhawatiran dalam kurangnya pemahaman mengenai pengembangan hasil bumi masyarakat kelurahan Nyapah serta menjadi merosotnya pengembangan pertanian dalam memanfaatkan perkebunan pisang dan terhadap berlangsungnya UMKM menjadi tantangan untuk mensosialisasikan dan menyebarluaskan bagaimana caranya dalam pengembangan pisang menjadi produk yang bisa menghasilkan ekonomi kreatif dalam masyarakat dan mampu membantu perekonomian pribadi maupun kelompok daerah. Salah satunya disini yaitu mengembangkan pisang menjadi Keripik Pisang gula aren (Banana Chip Aren Sugar) dan Puding Pisang (Banana Puding) menjadi bermanfaat dan lebih dikenal masyarakat luas. Khusunya bagi remaja yang memang mereka sebagai remaja diharuskan untuk menjadikan diri mereka kreatif serta inovatif. Dikarenakan cukup banyaknya masyarakat yang melakukan penanaman pisang dan kebetulan di kelurahan Nyapah ditemukan UMKM yang melakukan produksi pembuatan keripik.

Pertama melakukan tinjauan lokasi yang memang bertujuan untuk melakukan penelitian demi mengetahui kelemahan dan kelebihan apa saja yang ada dalam pengembangan potensi Pisang ini. Setelah melakukan tinjauan lokasi dan menemukan kelemahan yaitu masih kurang nya pengolahan dalam menghasilkan variant rasa, pengemasan ( packaging ) serta identitas produk belum terlihat 


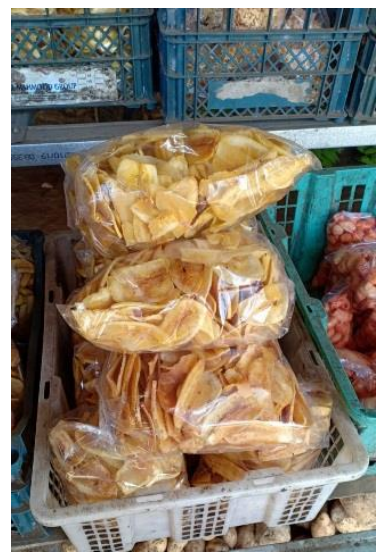

Gambar 1. Survei lokasi UMKM kripik pisang

Kedua memberikan penjelasan mengenai produk pisang dan mengembangkan melalui inovasi produk pisang yang dari produk sederhana hingga menjadi produk yang bisa mempunyai nilai lebih. Resep dan cara pembuatan untuk mendapatkan hasil yang sesuai sehingga bisa meningkatkan nilai jual produk dengan cara menambahkan varian rasa dalam keripik, membuat identitas produk dan pengemasan produk menjadi lebih menarik. Pengenalan dan penjelasan kepada masyarakat bahwa pisang ini tidak hanya bisa dijual sebagai keripik saja, di buat sebagai makanan pendamping pisang juga bisa diproduksi sebagai pudding pisang (Banana Puding) dan Smoothies Pisang, yang memiliki banyak manfaat untuk kesehatan. Dalam pemilihan pisang yang baik untuk pudding pisang, yaitu menggunakan Pisang Ambon dikarenakan manfaatnya yang cukup banyak untuk kesehatan. Tumbuhan pisang ambon memiliki banyak kandungan senyawa metabolit sekunder yang bermanfaat. Pada bagian buahnya diketahui memiliki kandungan saponin, glikosida, tannin, alkaloid, dan flavonoid (Ajani et al,2010). Selain kaya akan metabolit sekunder, buah pisang juga kaya akan kandungan kalium yang baik untuk hipertensi (Fatmawati dkk, 2017).

Dalam pengemasan menggunakan identitas, sehingga produk ini menjadi lebih mudah dikenal masyarakat dan dikembangkan karena proses pembuatan yang mudah, bahan yang mudah ditemukan di Kelurahan Nyapah dan bahan yang lainnya cukup ekonomis. 
Secara umum kegiatan pengabdian kepada Masyarakat ini bertujuan membertikan

pengetahuan, pemahaman serta pembinaan tentang pengembangan pengolahan produk kepada masyarakat dan UMKM yang ada, produk yang tidak hanya dapat meningkatkan nilai jual saja,

Melainkan menjadi makanan serta minuman yang memberikan kesehatan ketika dikonsumsi juga memberikan pengetahuan terkait alasan mengapa menjadikan keripik pisang gula aren dan apa saja manfaat serta kandungan gizi yang ada dalam gula aren.

Kandungan Gizi Gula Merah Aren

\begin{tabular}{|c|l|c|}
\hline No & \multicolumn{1}{|c|}{ Jenis kandungan } & Dalam 100 gr Gula Merah Aren \\
\hline 1 & Kalori & 368 Kalori \\
\hline 2 & Karbohidrat & 95 gram \\
\hline 3 & Kalsium & 75 miligram \\
\hline 4 & Fosfor & 35 miligram \\
\hline 5 & Besi & 3 miligram \\
\hline 6 & Air & 4 gram \\
\hline
\end{tabular}

Sumber: Dinas kesehatan

Manfaat Gula Aren Bagi Kesehatan

Gula aren memiliki beberapa manfaat bagi kesehatan, diantaranya:

1 Sumber Antioksidan

Untuk menangkal radikal bebas, sehingga dapat melindungi tubuh dari ancaman penyakit berbahaya seperti penyakit kanker kulit.

2 Mengobati dan Mencegah Anemia

Dikarenakan gula aren memiliki kandungan zat besi yang cukup tinggi.

3 Meningkatkan sistem kekebalan tubuh

4 Menstabilkan kadar kolestrol didalam tubuh

Dikarenakan gula aren memiliki kandungan niacin dan kandungan niacin ini juga berperan menghaluskan dan menjaga kesehatan kulit.

5 Meningkatkan sistem pencernaan

6 Melancarkan sirkulasi darah, dapat menurunkan berat badan, menghangatkan tubuh dan mengatasi sariawan.

\section{METODE}

Kegiatan Introduksi keripik Pisang Gula Aren, Smoothies pisang dan Banana Pudding dilakukan di 2 lokasi. Lokasi pertama dilakukan di tempat UMKM keripik Ibu Bunah tepatnya di Kelurahan Nyapah Pasar. Untuk lokasi kedua di pusat kegiatan kelompok tepatnya di Kelurahan Nyapah Kantor-Walantaka. Metode kegiatan terdiri dari sosialisasi, seminar 
UMKM dan Baksos Kesehatan serta pada saat Loka Karya Kelurahan. Penyebaran informasi melalui metode pada Seminar/sosialisasi tentang UMKM dan Baksos Kesehatan untuk penyebaran informasi mengenai proses pengemasan produk serta ijin usaha identitas produk pada saat sosialisasi bidang Hukum.

\section{CARA PEMBUATAN PRODUK}

- Keripik Pisang Gula Aren

- Pertama yaitu pembuatan keripik pisang yang pertama :

$\checkmark$ Siapkan pisangnya yaitu pisang nangka, sambil membersihkan kita siapkan air di dalam ember lalu masukkan kapur sirih.

$\checkmark$ Selanjutnya setelah pisang dikupas pisang direndam ke dalam kapur sirih tersebut.

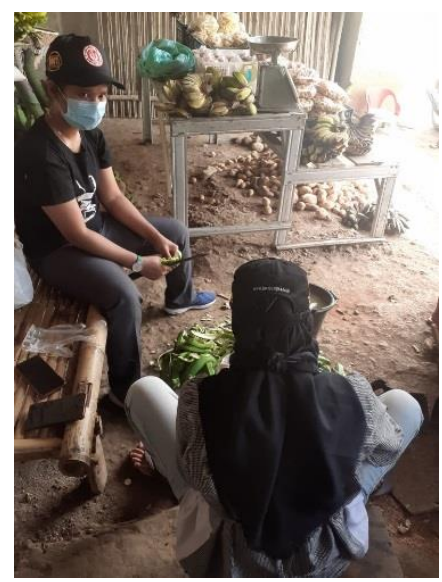

- Panaskan minyak dalam wajan setelah minyak panas, hasil rendaman pisang tadi diiris sambil dipotong di kedalam minyak yang panas tadi goreng pisang hingga pisang berwarna kecoklatan dan kering angkat pisang dan tiriskan.
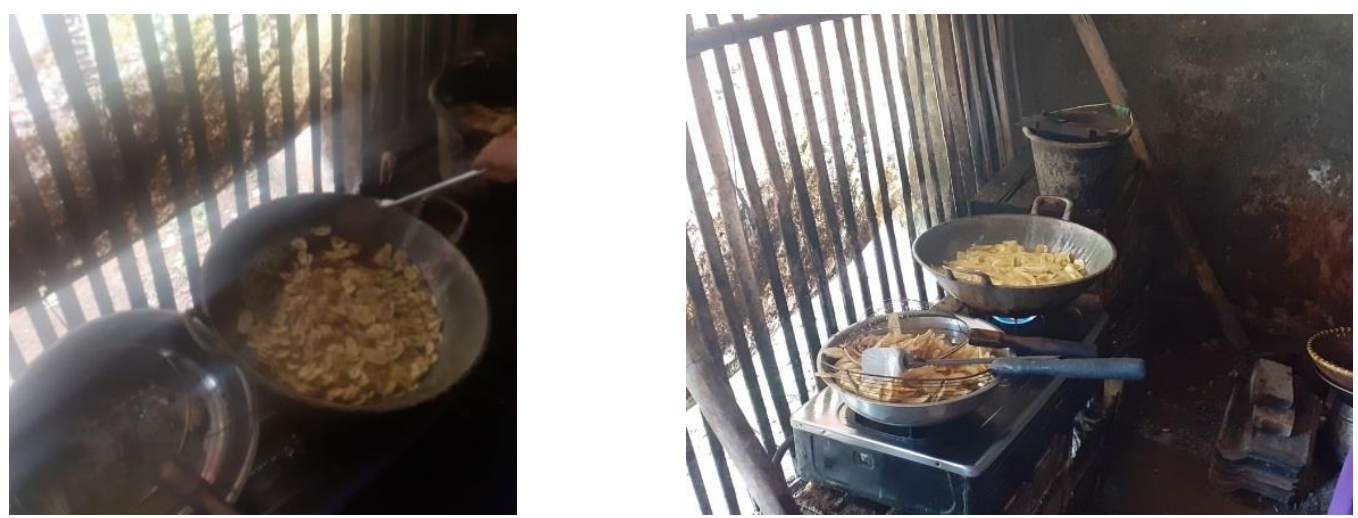
- Kedua yaitu cara pembuatan gula aren langkah yang kedua

$\checkmark$ Siapkan gula merah Aren air putih dan garam

Lelehkan gula merah ke dalam panci setelah gula merah meleleh siapkan wajan Panaskan di atas api paling kecil lalu masukkan 2 sendok gula merah 4 sendok air minum dan sejumput garam aduk masak hingga gula merah mengental

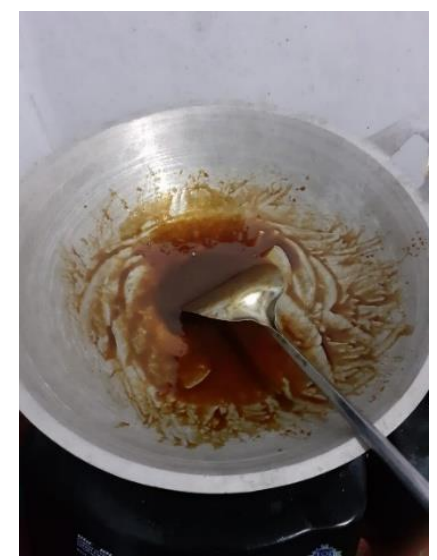

- Setelah mengental, masukkan keripik pisang tadi kira-kira setengah kilo kedalam gula merah lalu aduk dengan cepat hingga merata

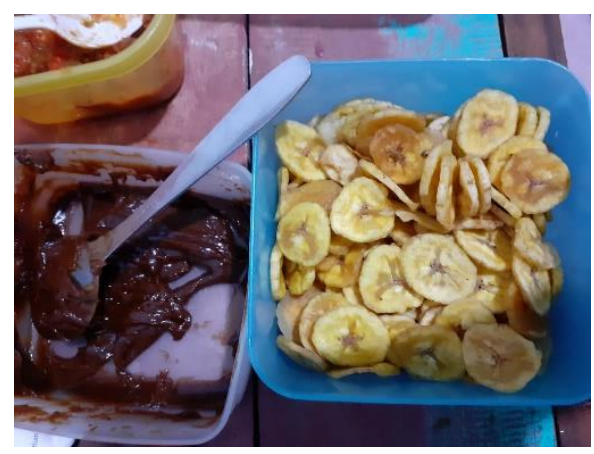

- Angkat keripik pisang tiriskan setelah Tiris masukkan ke dalam standing pouch atau kemasan lalu rapatkan klip kemasan dan berikan stiker atau identitas produk

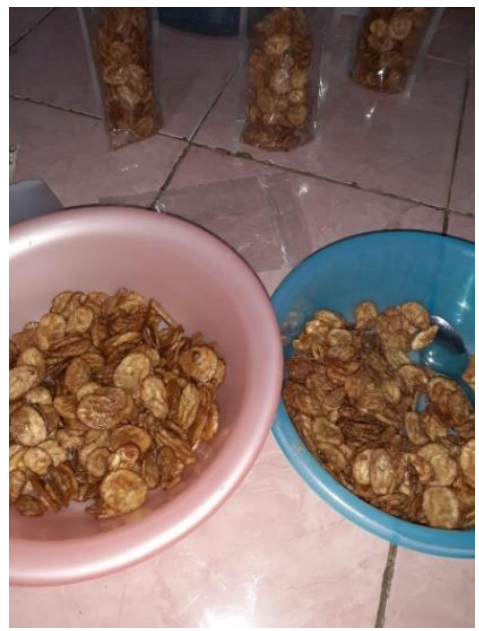


- Puding Pisang

- Cara pembuatan puding yang pertama yaitu pembuatan fla-fla ini kita siapkan panci, 3 susu kotak rasa pisang, 3 sachet susu kental manis putih. Lalu Panaskan diaduk rata sudah dirasa berbuih sudah berbuih larutkan 2 sendok maizena dalam piring kecil lalu masukkan ke dalam panci sesudah tadi aduk hingga mengental Lalu setelah mengental angkat dan masukkan ke dalam Cup ukuran $300 \mathrm{ml}$ kita bisanya pakai setengah dari kata tersebut

- Langkah kedua pembuatan pudingnya kita siapkan puding coklat masukkan ke dalam panci 5 gelas air gula secukupnya dan 3 sachet susu kental manis aduk puding beserta bahan-bahan yang lainnya hingga mendidih lalu kita blender pisang sekitar 5 pisang lalu masuk setelah halus masukkan kedalam puding tadi dan aduk hingga mendidih angkat lalu tuang ke dalam kap yang berisi tersebut Lalu diamkan setelah mengeras beri hiasan daun pandan di atasnya tutup kap dan beridentitas produk
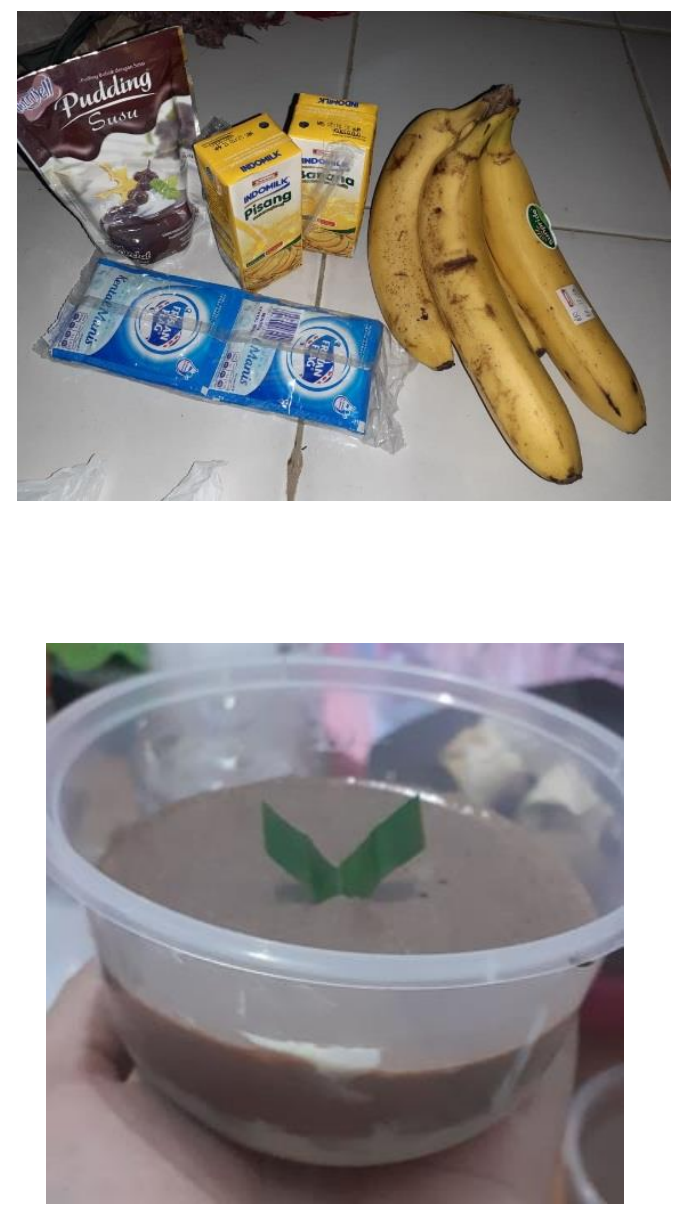


\section{HASIL DAN PEMBAHASAN}

Secara keseluruhan, kegiatan introduksi ini telah dapat meningkatkan pengetahuan dan pemahaman masyarakat terhadap pengembangan potensi masyarakat maupun tentang UMKM fokus produk dari buah pisang. Bahwa siapapun bisa membuat, menjadi dan menghasilkan sesuatu. Dalam penyebaran informasi salah satunya dengan melakukan kegiatan seminar dan baksos kesehatan tentang UMKM, dimana kami membahas mengenai arti pentingnya kesehatan dalam kehidupan serta memberi informasi tentang manfaat pisang yang dapat dijadikan berbagai olahan produk, seperti keripik pisang gula aren yang memberi banyak manfaat bagi kesehatan, memperkenalkan pula bahwa pisang dapat dijadikan smoothies pisang susu dan pudding pisang.

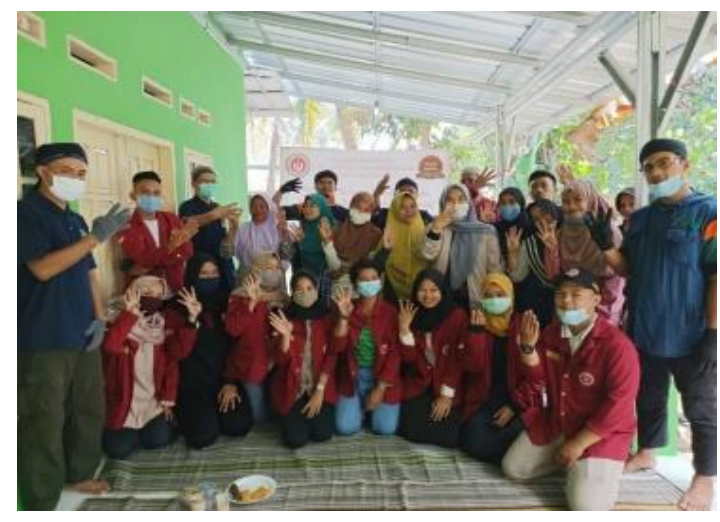

Gambar 2. Penyebaran Informasi tentang UMKM

Setelah memberikan informasi dengan melakukan seminar, kami juga membantu para masyarakat dengan memberi informasi mengenai pentingnya peran hukum dalam bidang UMKM, karena masih banyak UMKM yang kurang mengerti mengenai cara pemasaran yang baik serta perizinan ketetapan usaha milik pribadi atau kelompok.

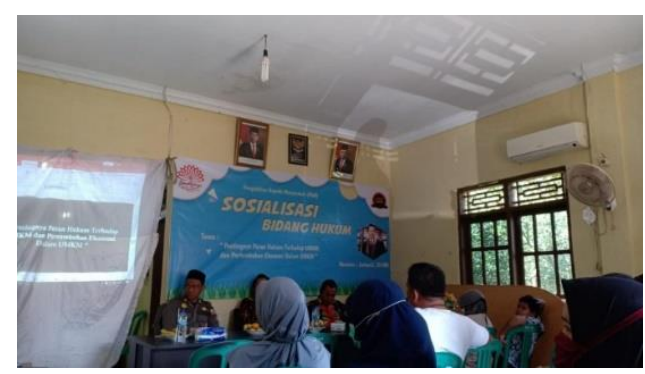

Gambar 3. Sosialisasi Pentingnya peran hukum dalam UMKM 
Proses setelah memberikan informasi yaitu dengan melakukan pembinaan bagi ibu-ibu dan remaja kelurahan nyapah, dimana kami membantu agar para masyarakat dapat melanjutkan pembuatan pruduk yang telah kami jelaskan guna membantu perekonomian keluarga mereka agar tetap stabil yaitu dengan membuka usaha menengah.

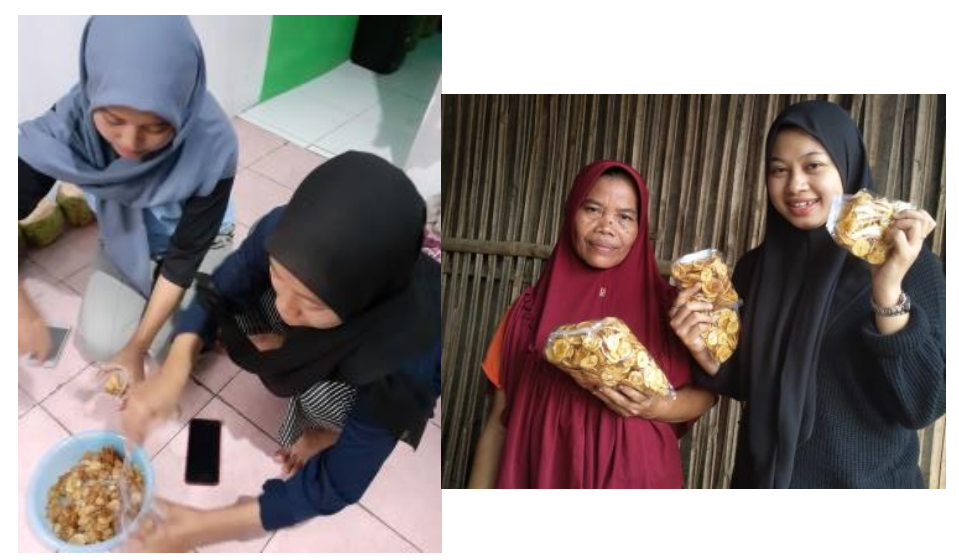

Gambar 4. Binaan UMKM

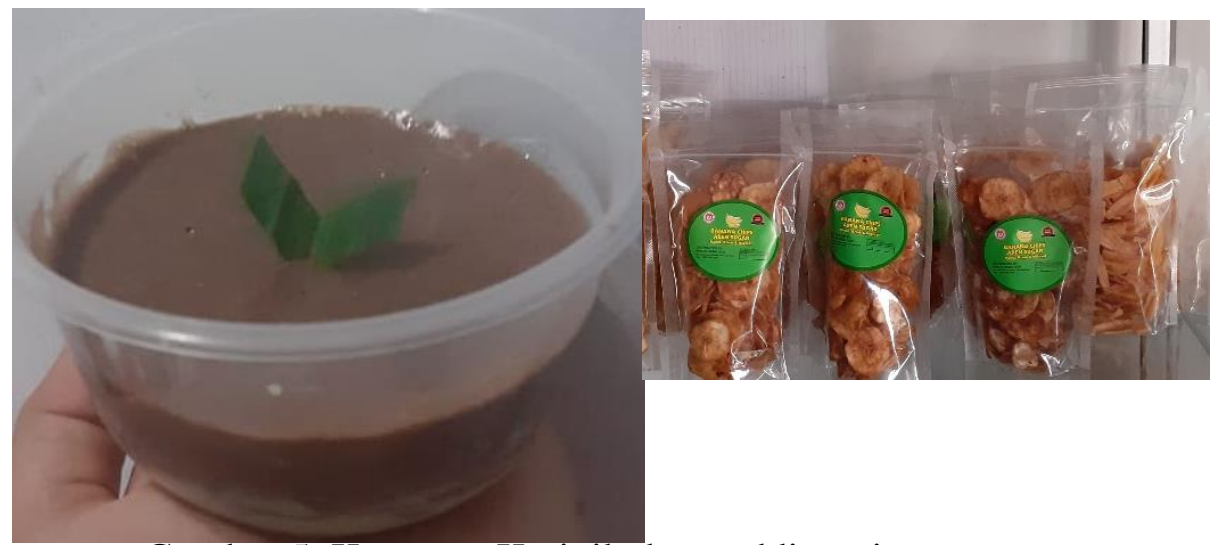

Gambar 5. Kemasan Keripik dan pudding pisang 


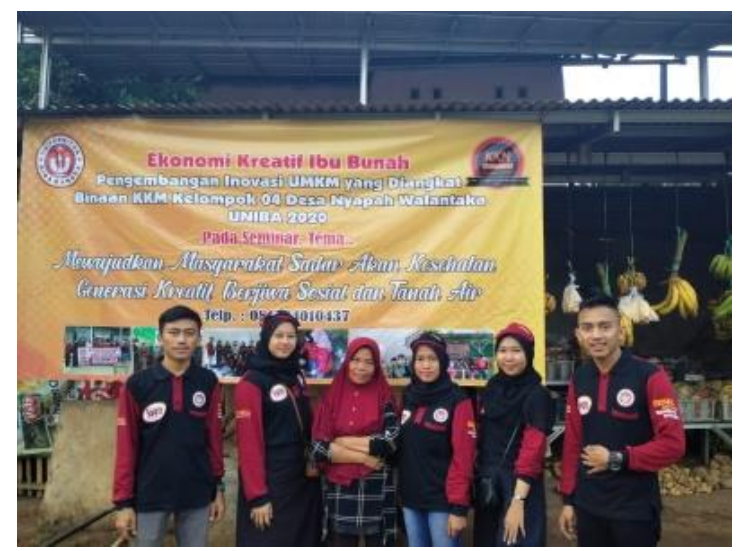

Gambar 6. Pemberian banner ke tempat UMKM Ibu Bunah

\section{KESIMPULAN}

Pengabdian terhadap Masyarakat Kelurahan Nyapah dalam bidang Ekonomi Kreatif meningkatkan pengetahuan masyarakat dan menjadikan pemikiran masyarakat untuk lebih bisa memanfaatkan hasil bumi mereka. Serta mengetahui manfaat, gizi yang terkandung dalam pisang menjadi berbagai macam makanan dan minuman yang bisa dikonsumsi yang menyehatkan ditengah situasi pandemic COVID 19 yang sangat dianjurakan menjaga kesehatan. Para remaja kelurahan Nyapah juga sudah mencoba mempraktekkannya dirumah. Bahkan pemilik UMKM keripik Ibu Bunah sudah mulai mencoba memprodusikan jual beli Keripik Pisang Gula Aren dari seminar yang sudah pernah diadakan oleh mahasiswa KKM 04. Jika untuk mengetahui lokasi pemasaran produknya ada di Kelurahan Nyapah PasarWalantaka. Hasil pengabdian ini diharapkan tidak hanya dipraktekkan oleh remaja saja tetapi oleh masyarakat seluruh Kelurahan Nyapah agar menjadikan masyarakat lebih aktif, kreatif dan diberdayakan sehingga dapat meningkatkan penghasilan keluarga maupun menambah skill para sumber daya manusianya. 
JABB, Vol. 01, No. 01, Juli, 2020

p-ISSN : 2722-936X e-ISSN: 2722-9394

DOI Issue : 10.46306/jabb.v1i1

Doi Artikel : 10.46306/jabb.v1i1.14

\section{DAFTAR PUSTAKA}

Heryani, H.2016.Keutamaan Gula Aren dan Strategi Pengembangan Produk. Diunduh pada 2020 sept 2800.34

Hisban HA.dkk. 2018. Karakteristik Dan Manfaat Tumbuhan Pisang. Farmaka. 16 (3): 197-198 